\title{
Effects of a Law against Early Postpartum Discharge on Newborn Follow-up, Adverse Events, and HMO Expenditures
}

\section{Citation}

Madden, Jeanne M., Stephen B. Soumerai, Tracy A. Lieu, Kenneth D. Mandl, Fang Zhang, and Dennis Ross-Degnan. 2002. "Effects of a Law Against Early Postpartum Discharge on Newborn Follow-up, Adverse Events, and HMO Expenditures." New England Journal of Medicine 347 (25) (December 19): 2031-2038. doi:10.1056/nejmsa020408.

\section{Published Version}

doi:10.1056/NEJMsa020408

\section{Permanent link}

http://nrs.harvard.edu/urn-3:HUL.InstRepos:32692605

\section{Terms of Use}

This article was downloaded from Harvard University's DASH repository, and is made available under the terms and conditions applicable to Other Posted Material, as set forth at http:// nrs.harvard.edu/urn-3:HUL.InstRepos:dash.current.terms-of-use\#LAA

\section{Share Your Story}

The Harvard community has made this article openly available.

Please share how this access benefits you. Submit a story.

Accessibility 
Special Article

\title{
EFFECTS OF A LAW AGAINST EARLY POSTPARTUM DISCHARGE ON NEWBORN FOLLOW-UP, ADVERSE EVENTS, AND HMO EXPENDITURES
}

\author{
Jeanne M. Madden, Ph.D., Stephen B. Soumeral, Sc.D., Tracy A. Lieu, M.D., M.P.H., \\ Kenneth D. Mandl, M.D., M.P.H., Fang Zhang, M.Sc., and Dennis Ross-Degnan, Sc.D.
}

\begin{abstract}
Background Concern about harm to newborns from early postpartum discharges led to laws establishing minimum hospital stays in the mid-1990s. We evaluated the effects of an early-discharge protocol (a hospital stay of one postpartum night plus a home visit) in a health maintenance organization (HMO) and a subsequent state law guaranteeing a 48-hour hospital stay.

Methods Using interrupted-time-series analysis and data on 20,366 mother-infant pairs with normal vaginal deliveries, we measured changes in length of stay, newborn examinations on the third or fourth day of life, and office visits, emergency department visits, and hospital readmissions for newborns. We also examined expenditures for hospitalizations and homebased care.
\end{abstract}

Results The early-discharge program increased the rate of stays of less than two nights from 29.0 percent to 65.6 percent $(P<0.001)$. The rate declined to 13.7 percent after the state mandate $(P<0.001)$. The rate of newborn examinations on the third or fourth day of life increased from 24.5 percent to 64.4 percent with the program $(P<0.001)$, then dropped to 53.0 percent after the mandate $(P<0.001)$ - changes that primarily reflected changes in the rate of home visits. The rate of nonurgent visits to a health center increased from 33.4 percent to 44.7 percent $(P<0.001)$ after the reduced-stay program was implemented. There were no significant changes in the rate of emergency department visits (quarterly mean, 1.1 percent) or rehospitalizations (quarterly mean, 1.5 percent). Results were similar for a vulnerable subgroup with lower incomes, younger maternal age, a lower level of education, or some combination of these characteristics. Average HMO expenditures on hospital and home-based services decreased by $\$ 90$ per delivery with the early-discharge program and increased by $\$ 100$ after the mandate.

Conclusions Neither policy appears to have affected the health outcomes of newborns. After the mandate, newborns were less likely to be examined as recommended on day 3 or 4 . Because of changes in hospital prices, the two policies had minimal effects on HMO expenditures for hospital and home-based services. (N Engl J Med 2002;347:2031-8.)

Copyright $\odot 2002$ Massachusetts Medical Society.
$\mathrm{I}$ $\mathrm{N}$ the early 1990s, discharge on the day after a normal vaginal delivery had become commonplace. ${ }^{1}$ In reaction, 41 states and the U.S. Congress enacted legislation, most of which mandated hospitalization coverage by insurers for at least 48 hours after a vaginal delivery.2,3 Managed-care organizations and advocates for "demedicalizing" childbirth have argued that most postpartum services could be provided safely at home. ${ }^{4}$ Critics have countered that early discharge is primarily aimed at cost containment and that complications in newborns might go undetected..$^{5,6}$

Guidelines of the American Academy of Pediatrics recommend at least 48 hours of postpartum hospitalization but add that earlier discharge is reasonable if newborns are examined again within 48 hours after discharge. ${ }^{7}$ Recent evidence-based recommendations have also included clinical follow-up for newborns on the third or fourth day after delivery, regardless of the length of the hospital stay. ${ }^{2,8-11}$ However, many states and the federal law do not address the issue of followup care. ${ }^{3}$

The evidence for and against early discharge remains inconclusive. ${ }^{9,12-14}$ Most studies have involved small groups of randomized volunteers ${ }^{15,16}$ or have used large data-base samples without control for possible effects of selection among newborns who are discharged early. Several studies have suggested that short stays are associated with an increased risk of death or readmission of the infant, ${ }^{17,18}$ whereas others have found no effect. ${ }^{19,20}$

In our study, we used interrupted-time-series analysis and an unusual natural experiment within a large Massachusetts health maintenance organization (HMO) to determine the effects of reductions by the $\mathrm{HMO}$ in the length of stay and a subsequent state law establishing a minimum stay. Our previous research

From the Department of Ambulatory Care and Prevention, Harvard Medical School and Harvard Pilgrim Health Care (J.M.M., S.B.S., T.A.L., F.Z., D.R.-D.), and Children's Hospital (K.D.M.) - all in Boston. Address reprint requests to Dr. Ross-Degnan at the Department of Ambulatory Care and Prevention, Harvard Medical School and Harvard Pilgrim Health Care, 133 Brookline Ave., 6th Fl., Boston, MA 02215, or at drossdeg@ hms.harvard.edu. 
has shown that rates of breast-feeding were not affected by either policy. ${ }^{21}$ In this article, we investigate the effects of these policies on lengths of stay, follow-up care for newborns, use of outpatient care and hospital-based services during the first 10 days of life, and expenditures for hospital and home-based maternity services.

\section{METHODS}

\section{Study Design}

Using data from a period of seven and a half years, we evaluated changes in the utilization of services for newborns and expenditures associated with the early-discharge program of the $\mathrm{HMO}$ and a subsequent state law establishing a minimum stay. Changes in utilization were estimated with interrupted-time-series analysis, in which rates during the three periods with distinct policies were compared. We evaluated the financial effects on the HMO by comparing expenditures among the periods, accounting for changes in utilization and average payments for home-based services and hospitalizations of different lengths for delivery.

\section{Setting and Interventions}

The setting of the study was Harvard Vanguard Medical Associates (HVMA), a large multispecialty group that was caring for about 300,000 persons insured by Harvard Pilgrim Health Care (HPHC) during the study period. The study was approved by the Human Studies Committee of HPHC. In 1994, HPHC-HVMA (at that time a single entity, the Harvard Community Health Plan) implemented the Reduced Obstetrical Length of Stay (ROLOS) program, with a standard of one night in the hospital after a normal vaginal delivery, subject to the discretion of attending clinicians. The program featured increased prenatal preparation and identification of social risk factors, detailed clinical criteria for discharge, a home visit by a nurse within 48 hours after discharge, and enhanced assistance with lactation. Previously, a one-night stay with a home visit plus 16 hours of homemaker services had been offered to women who had volunteered to be discharged early after delivery.

Massachusetts passed a law establishing a minimum hospital stay of 48 hours after vaginal delivery, effective February 1996, which put a stop to the ROLOS program after 15 months. Under this legislation, earlier discharge was permitted if a mother gave consent and was offered a home visit by a clinician. A federal minimum-stay law that took effect in January 1998 did not change the policy environment for our study population.

\section{Study Sample}

We collected data on births between October 1990 and March 1998 to women who were enrolled in HPHC-HVMA; this period included four years before the ROLOS program began and two years after the state legislation took effect. A total of 33,344 mothers were identified by claims codes specific to childbirth, and 30,228 newborns were identified by neonatal medical-records codes within 60 days after birth. In order to be included, infants were required to have HPHC insurance for at least 45 of the first 60 days of life and at least one documented medical encounter during the first 7 days (95.5 percent of newborns). The matched mother-infant pair, in which both had HPHC insurance and received medical care at HVMA, was the primary unit of analysis $(92.3$ percent of newborns). We excluded the 23.6 percent of deliveries that involved cesarean sections (20.0 percent), that were followed by a stay of more than four nights ( 0.3 percent), or that were followed by unequal stays by the mother and the infant $(3.2$ percent $)$. Such clinically complex cases were unaffected by the length-of-stay policies. There were 20,366 pairs remaining in the study, or 679 births per quarter on average during the 30 quarters of the study.

\section{Data Sources and Measures}

We defined the length of stay as the difference in days between the delivery date and the discharge date. "Short" stays were defined as stays involving fewer than two nights in the hospital. Data on home visits by outside nursing agencies, emergency department visits, and hospital readmissions were obtained from claims for reimbursement.

The HVMA Automated Medical Records System provided details about all encounters with patients, ${ }^{22}$ including home visits by staff nurses. In this system, health center visits were coded as nonurgent (those occurring on weekdays and usually for routine preventive care) or urgent (including some weekday visits plus all evening or weekend visits, usually for acute care). We examined utilization during the first 10 days after birth, a period that is likely to include adverse events related to the length of the hospitalization for delivery but unlikely to include the standard clinical examination of the newborn at two weeks of age. We also defined a measure of adherence to the evidence-based recommendation ${ }^{2,8-11}$ that newborns undergo clinical examination on the third or fourth day after birth.

We obtained data on payments for hospitalizations and homebased services from vendors' claims. Expenditures for home visits by HMO nurses and outside vendors were assumed to be similar. All amounts were converted to 1998 dollars with the use of the all-item urban Consumer Price Index.

Data on race, maternal age, and Medicaid enrollment were obtained from the HPHC membership files. Data on maternal parity, birth weight, gestational age, and five-minute Apgar score were derived from data on encounters stored in the medical records system, supplemented by hospital data. We used 1990 U.S. Census data to determine the income and level of educational attainment for the mother's census tract of residence.

\section{Statistical Analysis}

Outcomes of interest - length of stay, follow-up services used, urgent care visits, emergency-department visits, and readmissions - were aggregated into three-month intervals (for a total of 30 quarters). We first examined quarterly trends in demographic and clinical measures for discontinuities that could confound the results. We then used interrupted-time-series regression models ${ }^{23-25}$ to estimate changes in outcome that occurred after the policy changes. Our models included a constant, a base-line trend over time (to control for underlying secular trends), and terms estimating changes in the level and trend of outcome rates after the implementation of both the ROLOS program and the state mandate. Observations for the third quarter of 1994 and the first quarter of 1996 were omitted, because these transitional quarters were not clearly characterized by a single policy. Time-series analyses were conducted with the use of SAS Proc Autoreg. ${ }^{26}$ In instances in which changes in rates were detected, we report absolute percentage changes. All $\mathrm{P}$ values are two-sided.

We repeated all analyses for a subgroup of infants born to women who were potentially more vulnerable to the effects of the policies, defined as women who were enrolled in Medicaid, living in a low-income neighborhood (median household income, $<\$ 25,000$ ) or a neighborhood with a low level of education (one third or more of the residents 25 years of age or older with less than a high-school education), or less than 22 years of age.

To estimate the effects on cost, we compared the HMO's expenditures for hospitalizations and home-based services during the 12 months before and after each change of policy (excluding the transitional quarters), incorporating changes in the length of stay, utilization of services, and average payments.

\section{RESULTS}

\section{Characteristics of the Study Population}

Demographic and clinical characteristics of the study population are presented in Table 1. Coefficients of 
Table 1. Characteristics of the Overall Study Population and the Vulnerable Subgroup.*

\begin{tabular}{|c|c|c|}
\hline \multirow[t]{2}{*}{ CHARACtERISTIC } & $\begin{array}{l}\text { Overall Study } \\
\text { Population } \\
\text { (N=20,366) }\end{array}$ & $\begin{array}{l}\text { VULNERABLE } \\
\text { SUBGROUP } \\
\text { ( } \mathbf{N}=\mathbf{3 4 1 1})\end{array}$ \\
\hline & \multicolumn{2}{|c|}{ percent } \\
\hline \multicolumn{3}{|l|}{ Birth weight } \\
\hline$<2500 \mathrm{~g}$ & 2.7 & 3.8 \\
\hline $2500-2999 \mathrm{~g}$ & 12.9 & 18.0 \\
\hline$\geqslant 3000 \mathrm{~g}$ & 84.4 & 78.2 \\
\hline \multicolumn{3}{|l|}{ Gestational age } \\
\hline$<38 \mathrm{wk}$ & 6.6 & 8.0 \\
\hline $38-39 w k$ & 27.1 & 30.2 \\
\hline$\geqslant 40 \mathrm{wk}$ & 66.3 & 61.8 \\
\hline \multicolumn{3}{|l|}{ 5-Min Apgar score } \\
\hline$<8$ & 1.7 & 1.6 \\
\hline 8 & 6.7 & 6.4 \\
\hline $9-10$ & 91.6 & 92.1 \\
\hline \multicolumn{3}{|l|}{ Maternal age } \\
\hline$<22 \mathrm{yr}$ & 4.5 & 26.7 \\
\hline $22-29 \mathrm{yr}$ & 31.2 & 42.9 \\
\hline $30-34 \mathrm{yr}$ & 39.2 & 19.7 \\
\hline$\geqslant 35 \mathrm{yr}$ & 25.1 & 10.7 \\
\hline \multicolumn{3}{|l|}{ Maternal parity } \\
\hline Primiparous & 44.6 & 40.8 \\
\hline \multicolumn{3}{|l|}{ Race or ethnic group } \\
\hline Non-Hispanic white & 69.2 & 30.4 \\
\hline Black & 17.0 & 48.8 \\
\hline Asian & 6.6 & 5.2 \\
\hline Hispanic, nonblack & 4.9 & 13.5 \\
\hline Other & 2.2 & 2.2 \\
\hline \multicolumn{3}{|l|}{ Medicaid coverage } \\
\hline Enrolled in Medicaid & 6.7 & 40.2 \\
\hline \multicolumn{3}{|l|}{ Census tract of residence } \\
\hline Low income & 6.7 & 39.7 \\
\hline Low educational level & 19.9 & 51.7 \\
\hline
\end{tabular}

*The unit of analysis was the mother-infant pair. The vulnerable subgroup was defined by a maternal age of less than 22 years, enrollment in Medicaid, or residence in a low-income census tract (median 1990 household income, $<\$ 25,000$ ) or a census tract with a low educational level (one third or more of residents 25 years of age or older with less than a high-school diploma). Data on birth weight were missing for 159 mother-infant pairs; data on gestational age were missing for 3121 pairs; data on five-minute Apgar scores were missing for 1283 pairs; data on maternal age were missing for 9 pairs; data on maternal parity were missing for 4478 pairs; data on race or ethnic group were missing for 433 pairs; data on Medicaid coverage were missing for 11 pairs; data on census tract of residence were missing for 279 pairs.

variation over time for birth weight, gestational age, and five-minute Apgar score were less than 1 percent. Maternal age increased gradually from 30.2 years to 32.1 years by 1998. Quarterly deviations in the percentage of infants born to primiparous women (mean $[ \pm S \mathrm{SD}], 44.8 \pm 2.7$ percent) and in the percentage of black infants (mean, 17.1 \pm 2.3 percent) were small. Infants in the vulnerable subgroup (representing 16.7 \pm 2.3 percent of all births) were more likely to be black or Hispanic (62.3 percent vs. 21.9 percent overall) and small or premature.

\section{Changes in Postpartum Length of Stay}

Sudden large shifts in the length of the postpartum stay accompanied the two changes in policy (Fig. 1).
An average of 12.9 percent of infants born in normal vaginal deliveries between the fourth quarter of 1990 and the second quarter of 1992 had postpartum stays of less than two nights; the percentage subsequently increased steadily to 29.0 percent in the second quarter of 1994. With control for the base-line trend, the rate of short stays increased immediately after the implementation of the ROLOS program by 39.4 percentage points $(\mathrm{P}<0.001)$. While the ROLOS program was in effect, the rate of short stays averaged 65.6 percent. After the state mandate went into effect, the proportion of short stays dropped sharply by 42.2 percentage points $(\mathrm{P}<0.001)$, and the average over the following two years was 13.7 percent of births. (A slight downward trend throughout both the period when the ROLOS program was in place and the period after the mandate was estimated as a decrease of 1.1 percentage points per quarter $[\mathrm{P}<0.001]$.) Rates of short stays among the vulnerable subgroup mirrored those in the overall population (Fig. 1), averaging 63.4 percent during the ROLOS program and 15.1 percent after the mandate.

\section{Changes in Early Clinical Follow-up in Newborns}

Examinations of newborns on day 3 or 4 could occur during long hospitalizations for delivery, visits to the health center, or home visits by nurses (Fig. 2). At base line, the percentage with follow-up examinations on day 3 or 4 was stable at 24.5 percent; it increased suddenly by 39.9 percentage points (to 64.4 percent) after the implementation of the ROLOS program $(\mathrm{P}<0.001)$. The state mandate was associated with a sudden drop of 11.4 percentage points in the rate of follow-up examinations on day 3 or $4(\mathrm{P}<0.001)$, resulting in a rate of 53.0 percent for the final period. In the vulnerable subgroup, the base-line rate and ROLOS-associated change in the rate of follow-up examinations on day 3 or 4 were nearly identical to those in the overall population, but the decline after the mandate was less pronounced (rate for the final period, 56.2 percent).

During the ROLOS program, 90.2 percent of all infants with short stays and 44.8 percent of all infants with longer stays received a home visit from a nurse within a week after discharge. For the two years after the mandate, these proportions were 83.2 percent and 37.4 percent, respectively.

\section{Changes in Utilization of Health Center Services for Newborns}

During their first 10 days, 33.2 percent of the newborns in the study had a nonurgent visit at the health center, and 7.4 percent had an urgent visit (Fig. 3). We estimated that there was a steady increase in the rate of nonurgent visits from 25.7 percent at the start of the study to 33.4 percent just before the implemen- 


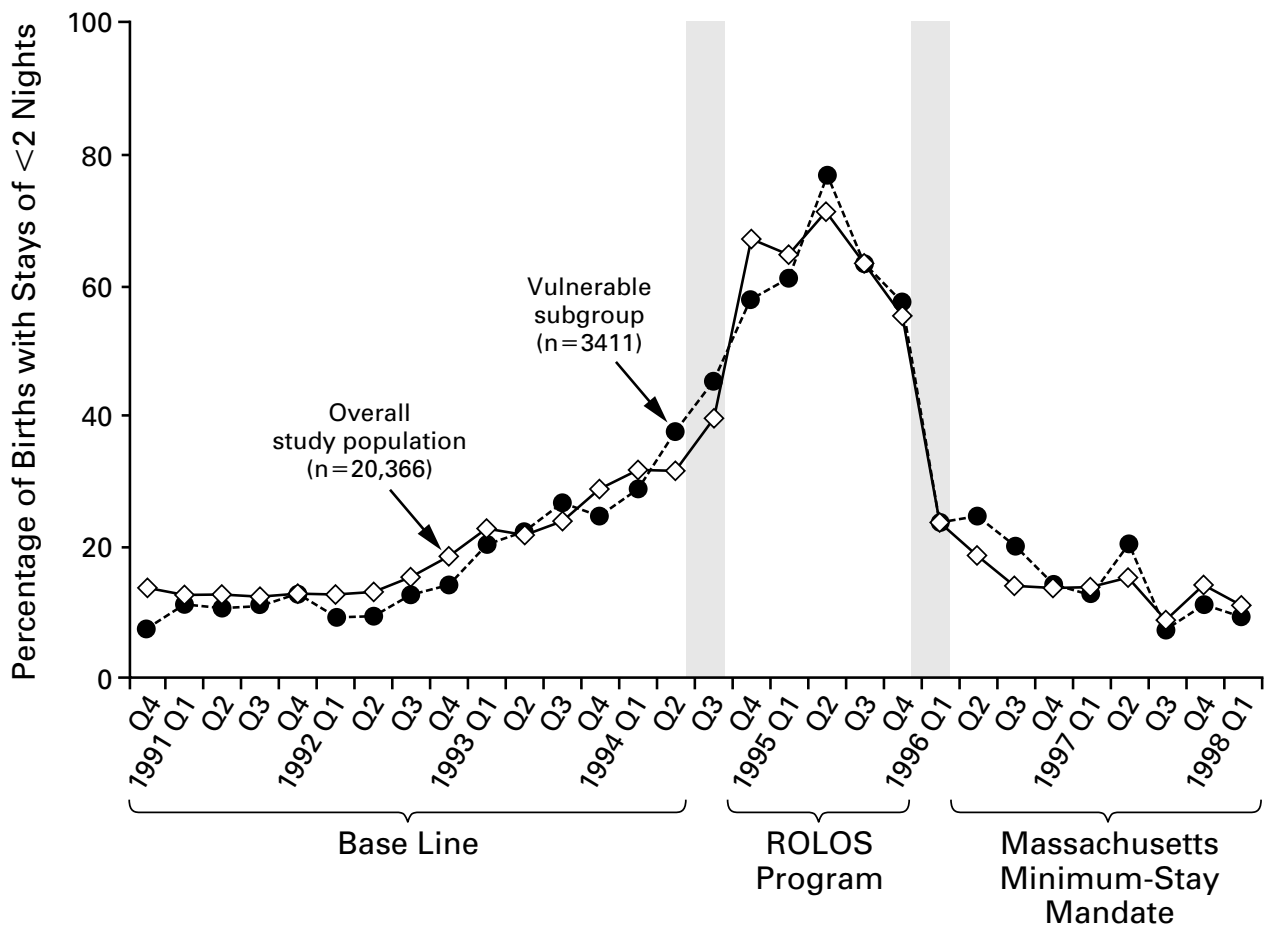

Figure 1. Time Series of the Percentage of 20,366 Newborns with Normal Vaginal Deliveries Who Had Short Postpartum Hospital Stays, for the Overall Study Population and the Vulnerable Subgroup.

The vulnerable subgroup was defined by a maternal age of less than 22 years, enrollment in Medicaid, or residence in a low-income census tract (median 1990 household income, $<\$ 25,000$ ) or a census tract with a low educational level (one third or more of residents 25 years of age or older with less than a high-school diploma). $\mathrm{Q}$ denotes quarter, and ROLOS Reduced Obstetrical Length of Stay. The shaded bars represent transitional quarters between policy periods.

tation of the ROLOS program $(\mathrm{P}=0.002)$. After the program was implemented, the rate of nonurgent visits increased by 10.2 percentage points more than it would have been expected to increase had the base-line trend continued $(\mathrm{P}<0.001)$; the rate reached 44.7 percent in the fourth quarter of 1994, then began a slow decrease of 1.0 percentage point per quarter $(\mathrm{P}<$ 0.001 ) that continued during the period after the mandate. There were no sudden changes in the rate of urgent visits associated with the shifts in policy. The rate of urgent visits began at 5.2 percent, increased by 0.2 percent per quarter during the base-line and ROLOS periods $(\mathrm{P}<0.001)$, and declined by 0.2 percentage point per quarter $(\mathrm{P}=0.001)$ after the mandate.

Rates and trends for urgent visits in the vulnerable subgroup were the same as those for the overall population during all periods. The rate of nonurgent visits was 5.7 percent lower for the vulnerable subgroup before the ROLOS program $(\mathrm{P}<0.001)$ but was statistically identical to the rate in the overall population both during the ROLOS program and after the mandate.

\section{Hospital Utilization by Newborns}

We examined hospital readmissions and emergency department visits without readmission through the 10th day of life (Fig. 3). The rate of emergency department visits not resulting in admission was constant at 1.1 percent of newborns, with no changes associated with either change of policy. The rate of readmissions to the hospital remained flat at 1.5 percent during all three periods. Most readmissions (71.0 percent) began with a visit to the emergency department. In the vulnerable subgroup, the overall rates of emergency department visits and rehospitalization were 1.0 percent and 1.4 percent, respectively, but the numbers were too small to permit statistical time-series analysis.

\section{Effect of Policy Changes on Expenditures by the HMO}

Average hospital payments for postpartum stays are presented in Table 2. If the price structure that was in place during the 12 months before the implementation of the ROLOS program had remained stable during subsequent years, the observed changes in the length of postpartum stay and the use of home-based services would have resulted in a savings to the HMO 


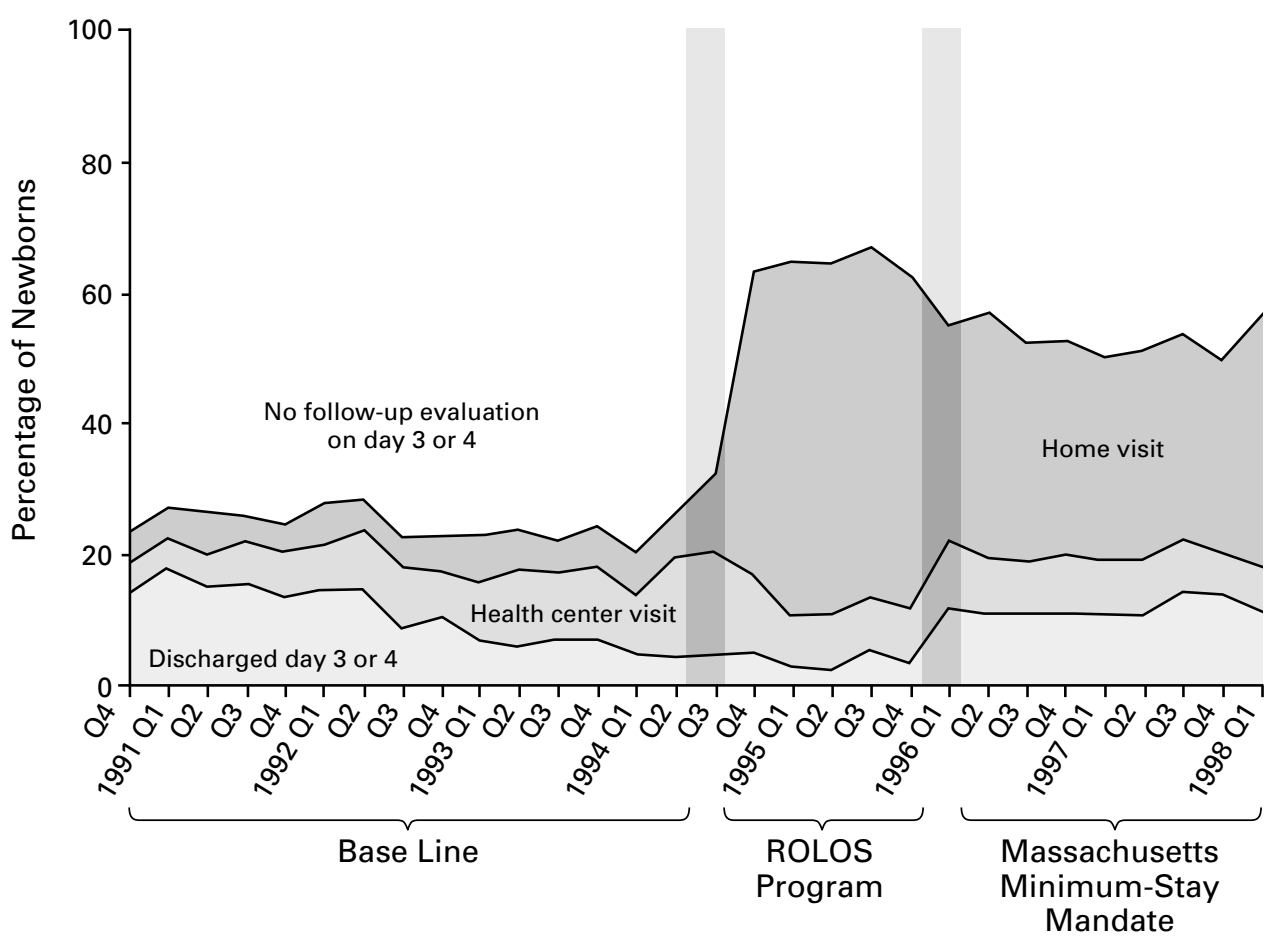

Figure 2. Time Series of Percentage of 20,366 Newborns with Normal Vaginal Deliveries Who Underwent Clinical Evaluation on the Third or Fourth Day of Life, According to Location.

Data are for the overall study population. Locations of follow-up are mutually exclusive. Newborns were classified under "home visit" if they received a home visit on the day of or the day before a visit to the health center. $Q$ denotes quarter, and ROLOS Reduced Obstetrical Length of Stay. The shaded bars represent transitional quarters between policy periods.

of $\$ 380$ per mother during the ROLOS program and an increase of $\$ 558$ after the Massachusetts mandate. However, the average payment for a one-night stay increased sharply during the ROLOS program, reducing the price differential between a one-night hospitalization and a two-night hospitalization from a constant estimate of $\$ 1,060$ during the four years before the program to $\$ 410$ during the two years after the mandate $(\mathrm{P}<0.001)$. One-night and two-night stays constituted 90.1 percent of all stays among women in our study population.

Taking into account these changes in utilization and prices, we estimated that the average expenditure for hospitalization plus home-based services decreased from $\$ 2,599$ in the 12 months before the ROLOS program to $\$ 2,509$ during the program - a savings to the HMO of only $\$ 90$ per delivery (Table 2). After the mandate and the resultant sudden increase in the rate of longer stays, payments for the average delivery increased by $\$ 100$ to $\$ 2,609$, or $\$ 10$ more than outlays before the ROLOS program, with adjustment for inflation. These analyses do not account for changes in the utilization of the health center for newborns (in- cluding office visits or telephone calls ${ }^{27}$ ) or for other program-related costs (Table 2).

\section{DISCUSSION}

As expected, the early-discharge program of the HMO substantially increased the proportion of births followed by short stays, and subsequent legislation in Massachusetts reversed these increases. The rate of home visits by nurses also rose sharply during the ROLOS program, but the decrease that occurred after the law went into effect was less substantial - probably because home visits proved popular among families and clinicians and because the law guaranteed home-visit coverage after any stay of less than 48 hours. After the law took effect, many women could stay two full nights after delivery and still receive a home visit.

The rate of clinical follow-up on the third or fourth day of life - a time when both breast-feeding difficulties and the incidence of jaundice peak $2,8,28$ - increased as a result of efforts associated with the shortstay program but decreased when the mandate took effect. There were similar findings for the vulnerable 

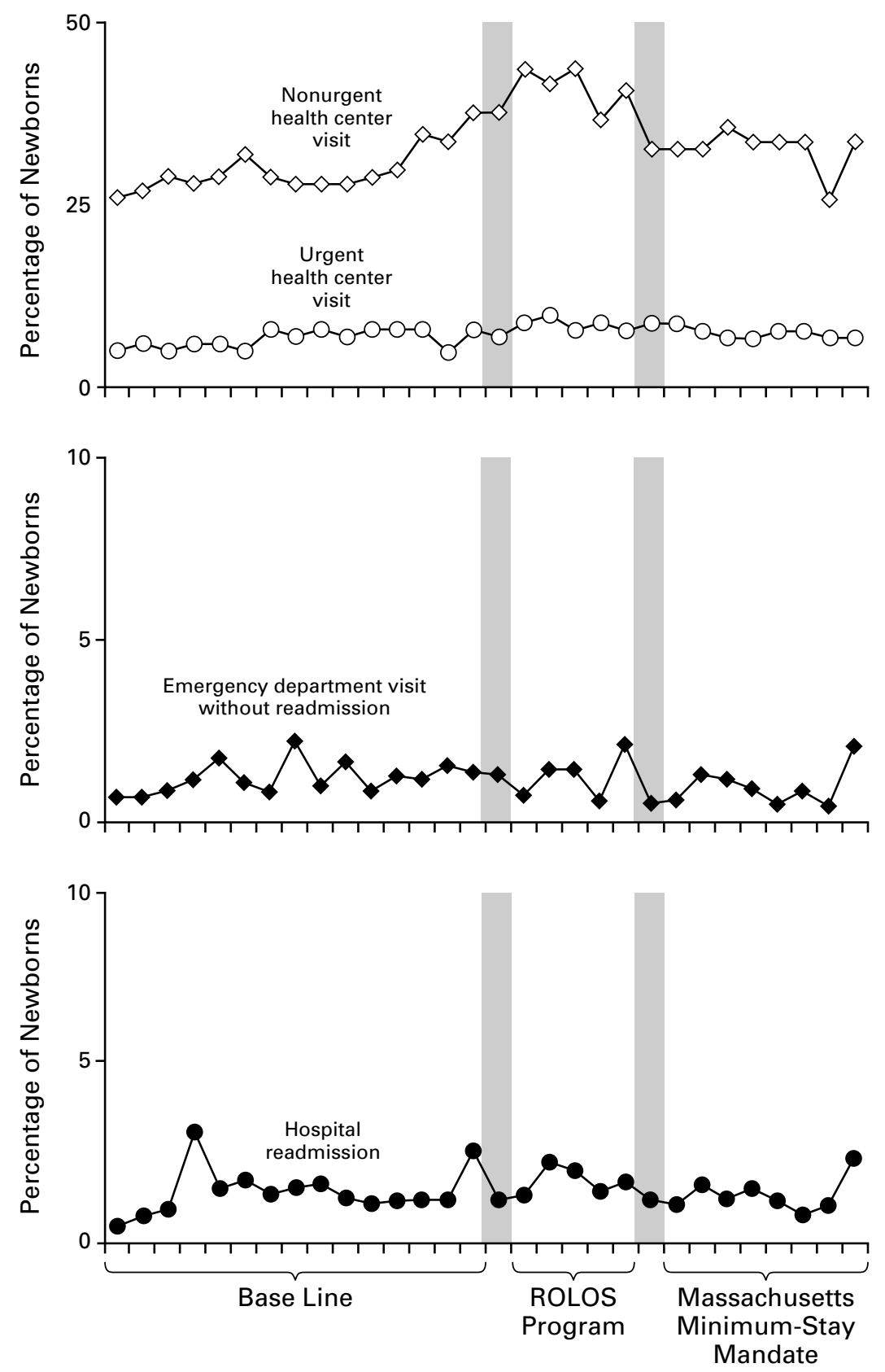

Figure 3. Time Series of the Percentages of 20,366 Newborns with Normal Vaginal Deliveries Who Had Urgent and Nonurgent Ambulatory Visits, Emergency Department Visits, or Hospital Readmissions during the First 10 Days of Life, According to Quarter from October 1990 through March 1998.

Data are for the overall study population. The groups with urgent and nonurgent visits are mutually exclusive; only the initial visits by newborns to health centers have been counted. ROLOS denotes Reduced Obstetrical Length of Stay. The shaded bars represent transitional quarters between policy periods. 
Table 2. Average HMO Expenditures for Normal VAginal Deliveries.*

\begin{tabular}{|c|c|c|c|}
\hline \multirow[t]{2}{*}{ TYPE OF SERVICE } & $\begin{array}{l}\text { Before ROLOS } \\
\text { Program }\end{array}$ & $\begin{array}{l}\text { DURING ROLOS } \\
\text { PROGRAM }\end{array}$ & $\begin{array}{c}\text { AFTER } \\
\text { MANDATE }\end{array}$ \\
\hline & \multicolumn{3}{|c|}{$\begin{array}{c}\text { average } \$ \text { expenditure } \\
\text { (\% of mothers receiving service) }\end{array}$} \\
\hline \multicolumn{4}{|l|}{$\begin{array}{l}\text { No. of postpartum nights } \\
\text { in hospital stay } \dagger\end{array}$} \\
\hline 0 & $1,805(1)$ & $1,990(1)$ & $2,351(0)$ \\
\hline 1 & $1,736(29)$ & $2,205(63)$ & $2,174(15)$ \\
\hline 2 & $2,767(65)$ & $2,796(33)$ & $2,548(74)$ \\
\hline 3 & $3,867(5)$ & $3,781(3)$ & $3,288(10)$ \\
\hline 4 & $5,358(0)$ & $4,425(0)$ & $4,443(0)$ \\
\hline \multicolumn{4}{|c|}{ Home-based care services $\ddagger$} \\
\hline Visit by nurse & $88(14)$ & $74(76)$ & $70(45)$ \\
\hline Homemaker services & $430(13)$ & - & - \\
\hline Total\$ & $2,599(100)$ & $2,509(100)$ & $2,609(100)$ \\
\hline
\end{tabular}

*For this analysis, the period we studied before the implementation of the Reduced Obstetrical Length of Stay (ROLOS) program was the third quarter of 1993 through the second quarter of 1994; the program period included the first quarter of 1995 through the fourth quarter of 1995; the period after the Massachusetts minimum-stay mandate included the second quarter of 1996 through the first quarter of 1997. All amounts are in 1998 dollars.

†Payments for claims for services provided to mothers were averaged separately for each length-of-stay category within each 12 -month period. Additional payments for claims for services provided to some infants were averaged across all stays within a period. Hospitalizations for delivery that included more than three nights in the hospital before delivery were excluded from the calculation of average expenditures.

$\ddagger$ Data are for home visits by nurses occurring within one week after discharge. Homemaker services were offered as an incentive for early discharge before the ROLOS program and were discontinued when the program was implemented. The 1996 Massachusetts law prohibited the use of incentives for early discharge.

$\$$ Data are for the average total HMO expenditure per delivery, including the hospital stay and home services, calculated on the basis of the prices and rates of utilization shown. Costs excluded from analysis included ongoing professional obstetrical services; investments in the planning and implementation of the ROLOS program and in related clinician training; and recurrent costs associated with added prenatal classes, elimination of class fees, social-risk screening protocols, and enhanced lactation services.

subgroup and in analyses in which newborns with a short stay were examined separately. The reduction in the rate of early follow-up care that occurred after the mandate took effect provides an example of the unintended negative consequences of regulatory policies, even in a state where the postpartum-stay law addressed the issue of follow-up care.

Emergency department visits and hospital readmissions - important proxy measures of health status were not significantly affected by the changes in policy. Because rates of readmission were low and quarter-toquarter variability was relatively high, our study could detect changes in the rate of readmissions of about 0.6 percentage point or four newborns per quarter. Thus, we cannot rule out small changes in the rates of these adverse outcomes. However, these events were distributed over all categories of length of stay, not concentrated among newborns with short stays. (During the ROLOS program, the proportion of newborns readmitted was 2.0 percent among newborns with longer stays and 1.7 percent among those with short stays; during the other two periods when ROLOS was not in effect, the rates were 1.4 percent and 1.7 percent, respectively.)

Increases in the rate of visits to the health center around the time when the early-discharge program was implemented were most likely attributable to three factors: deliberate, program-related efforts to encourage clinical contact after discharge; a longer interval between discharge and the 10th day of life; and an increase in referrals by nurses during home visits.

We were surprised that the early-discharge program was ineffective at reducing the maternity-related costs of the HMO. If a full accounting of costs were possible (including investments in the program and the cost of increased use of health centers), it might well reveal that the early-discharge program lost money. In an apparent response to the ROLOS program, some contracting hospitals altered their prices, narrowing the difference between the cost of short stays and the cost of longer stays. These price increases were compounded by legislation reinstituting a two-night norm, often still accompanied by a home visit. As a result, key maternity-related expenditures were not only higher than they had been during the ROLOS program, but also higher than they had been before the program. However, none of the observed changes were large in comparison with overall expenditures by the HMO for maternity care - approximately $\$ 4,550$ per woman, including hospitalizations and home visits plus professional obstetrical services (data not shown).

The strengths of our study are its large, stable, and diverse population, rich sources of data, and sharply delineated reversals in policy, permitting a quasi-experimental design free of many of the selection biases that plague nonrandomized policy studies. ${ }^{29}$ There were no demographic shifts to confound results, and we focused separately on potentially vulnerable subgroups.

One potential limitation of our study relates to its generalizability. Births to teenage mothers and Medicaid recipients were underrepresented in our population as compared with Massachusetts or the nation as a whole. Our subgroup analyses indicate that results were similar for less advantaged patients, although our census-based socioeconomic measures are imperfect and likely to misclassify some infants. Our sample included few low-birth-weight newborns, because we deliberately excluded clinically complicated births in order to isolate the effect of the policies within the population that was in fact affected by them. This HMO may have been unusual and may have assigned a higher priority to quality of care than to cost savings when implementing the early-discharge program. In 
other settings in which priorities differed, early-discharge programs may have had adverse effects, and the government intervention may have had protective effects. Elsewhere, substantial savings may have accompanied shortened stays, at least before the passage of minimum-stay legislation. Contractual arrangements between HMOs and health care providers are primary drivers of such economic outcomes. Our cost analyses do not account for savings that may have been realized by hospitals during the ROLOS program, increases in utilization of the health center, or potential changes in costs borne by families.

In summary, although both the reduced-stay program and the state mandate resulted in marked changes in practice, we found no effect of either policy on neonatal health after discharge (as measured by the use of hospital-based services). Our findings thus support previous research concluding that early discharge after delivery may be safe. ${ }^{19-21,30}$ Our results further indicate that, contrary to common assumptions, earlydischarge programs did not always save money for insurers, nor did minimum-stay legislation necessarily impose a large financial burden on insurers. One disturbing finding, however, was that progress in the quality of care associated with the reduced-stay program (evaluations of newborns on day 3 or 4) was partially eroded by the state mandate, leaving unanswered the question of whether the overall effects of the legislation were protective, as intended.

Supported by a grant (5ROlHS10060) from the Agency for Healthcare Research and Quality, by the Harvard Pilgrim Health Care Foundation, and by a grant (H16MC00050) from the Maternal and Child Health Bureau. Presented in part at the Meeting of the Secretary's Advisory Committee on Infant Mortality, Department of Health and Human Services, Washington, D.C., February 26-27, 2001; the Meeting of Child Health Services Researchers, Atlanta, June 9, 2001; and the Meeting of the Academy for Health Services Research and Health Policy, Washington, D.C., June 23-25, 2002.

We are indebted to Inna Dashevsky for assistance with data-set extraction and creation; and to many researchers, clinicians, and policy experts at Harvard University, Harvard Pilgrim Health Care, and Harvard Vanguard Medical Associates for their helpful comments on this work - in particular, Joseph L. Dorsey, M.D., and Joseph P. Newhouse, Ph.D.

\section{REFERENCES}

1. Trends in length of stay for hospital deliveries - United States, 19701992. MMWR Morb Mortal Wkly Rep 1995;44:335-7.

2. Eaton AP. Early postpartum discharge: recommendations from a preliminary report to Congress. Pediatrics 2001;107:400-3.

3. Thilo EH, Townsend SF, Merenstein GB. The history of policy and practice related to the perinatal hospital stay. Clin Perinatol 1998;25:25770.
4. Martell LK. The hospital and the postpartum experience: a historical analysis. J Obstet Gynecol Neonatal Nurs 2000;29:65-72.

5. Charles S, Prystowsky B. Early discharge, in the end: maternal abuse, child neglect, and physician harassment. Pediatrics 1995;96:746-7.

6. Declercq E, Simmes D. The politics of "drive-through deliveries": putting early postpartum discharge on the legislative agenda. Milbank Q 1997; 75:175-202.

7. Hospital stay for healthy term newborns. Pediatrics 1995;96:788-90.

8. Breastfeeding and the use of human milk. Pediatrics 1997;100:1035-9.

9. Braveman P, Kessel W, Egerter S, Richmond J. Early discharge and evidence-based practice: good science and good judgment. JAMA 1997;278: 334-6.

10. Maisels MJ, Kring E. Length of stay, jaundice, and hospital readmission. Pediatrics 1998;101:995-8.

11. Kernicterus threatens healthy newborns. Jt Comm Perspect 2001;21: $10-1$.

12. Britton JR, Britton HL, Beebe SA. Early discharge of the term newborn: a continued dilemma. Pediatrics 1994;94:291-5.

13. Braveman P, Egerter S, Pearl M, Marchi K, Miller C. Problems associated with early discharge of newborn infants: early discharge of newborns and mothers: a critical review of the literature. Pediatrics 1995;96:716-26. 14. Brumfield CG. Early postpartum discharge. Clin Obstet Gynecol 1998;41:611-25.

15. Carty EM, Bradley CF. A randomized, controlled evaluation of early postpartum hospital discharge. Birth 1990;17:199-204.

16. Gagnon AJ, Edgar L, Kramer MS, Papageorgiou A, Waghorn K, Klein MC. A randomized trial of a program of early postpartum discharge with nurse visitation. Am J Obstet Gynecol 1997;176:205-11.

17. Liu LL, Clemens CJ, Shay DK, Davis RL, Novack AH. The safety of newborn early discharge: the Washington State experience. JAMA 1997; 278:293-8. [Erratum, JAMA 1997;278:2067.]

18. Malkin JD, Garber S, Broder MS, Keeler E. Infant mortality and early postpartum discharge. Obstet Gynecol 2000;96:183-8.

19. Edmondson MB, Stoddard JJ, Owens LM. Hospital readmission with feeding-related problems after early postpartum discharge of normal newborns. JAMA 1997;278:299-303.

20. Kotagal UR, Atherton HD, Eshett R, Schoettker PJ, Perlstein PH. Safety of early discharge for Medicaid newborns. JAMA 1999;282:1150-6. 21. Madden JM, Ross-Degnan D, Lieu TA, Finkelstein JA, Mandl KD, Soumerai SB. Investigating the effects of maternity length of stay policies on breastfeeding rates through text search of medical records. Presented at the 6th Annual HMO Research Network Conference, Atlanta, April 4-5, 2000. abstract.

22. Platt R. Harvard Community Health Plan. In: Strom BL, ed. Pharmacoepidemiology. 2nd ed. Chichester, England: John Wiley, 1994:277-87. 23. Gillings DB, Makuc D, Siegel E. Analysis of interrupted time series mortality trends: an example to evaluate regionalized perinatal care. Am J Public Health 1981;71:38-46.

24. Soumerai SB, Avorn J, Ross-Degnan D, Gortmaker S. Payment restrictions for prescription drugs under Medicaid: effects on therapy, cost, and equity. N Engl J Med 1987;317:550-6.

25. Ross-Degnan D, Soumerai SB, Fortess EE, Gurwitz JH. Examining product risk in context: market withdrawal of zomepirac as a case study. JAMA 1993;270:1937-42.

26. SAS/ETS user's guide, version 6. 2nd ed. Cary, N.C.: SAS Institute, 1993

27. Mandl KD, Homer CJ, Harary O, Finkelstein JA. Effect of a reduced postpartum length of stay program on primary care services use by mothers and infants. Pediatrics 2000;106:Suppl:937-41.

28. Lawrence RA, Lawrence RM. Breastfeeding: a guide for the medical profession. 5th ed. St. Louis: Mosby, 1999.

29. Cook TD, Campbell DT. Quasi-experimentation: design \& analysis issues for field settings. Boston: Houghton Mifflin, 1979.

30. Mandl KD, Brennan TA, Wise PH, Tronick EZ, Homer CJ. Maternal and infant health: effects of moderate reductions in postpartum length of stay. Arch Pediatr Adolesc Med 1997;151:915-21.

Copyright (C) 2002 Massachusetts Medical Society. 